ИЗВЕСТИЯ АКАДЕМИИ НАУК ЭСТОНСКОИ ССР. ТОМ 20 ХимИЯ * ГЕОЛОГИЯ. 1971, № 1

\title{
О НЕКОТОРЫХ РАССЕЯННЫХ ЭЛЕМЕНТАХ В ГАЛЕНИТАХ И СФАЛЕРИТАХ ЭСТОНИИ
}

О составе рассеянных элементов в галенитах и сфалеритах свинцовоцинковых рудопроявлений Әстонской ССР еще мало сведений. В связи с этим нашей целью будет представить некоторые сведения о наличии и характере распространения элементов примесей в сульфидных минералах свинца и цинка, а также обсудить условия образования сульфидных минералов.

Минералогический материал для изучения рассеянных элементов был собран автором в течение нескольких лет из следующих тектонически трещиноватых зон Центральной Эстонии: новое русло р. Навести в районе Выхма, обнажение на берегу ручейка Соомевере, разведочные шурфы Курепыллу, буровые скважины и обнажение Ваки, а в СевероВосточной Әстонии из карьеров горючих сланцев Вийвиконна, Сиргала, а также буровых скважин Ульясте и Палукюла (см. рисунок).

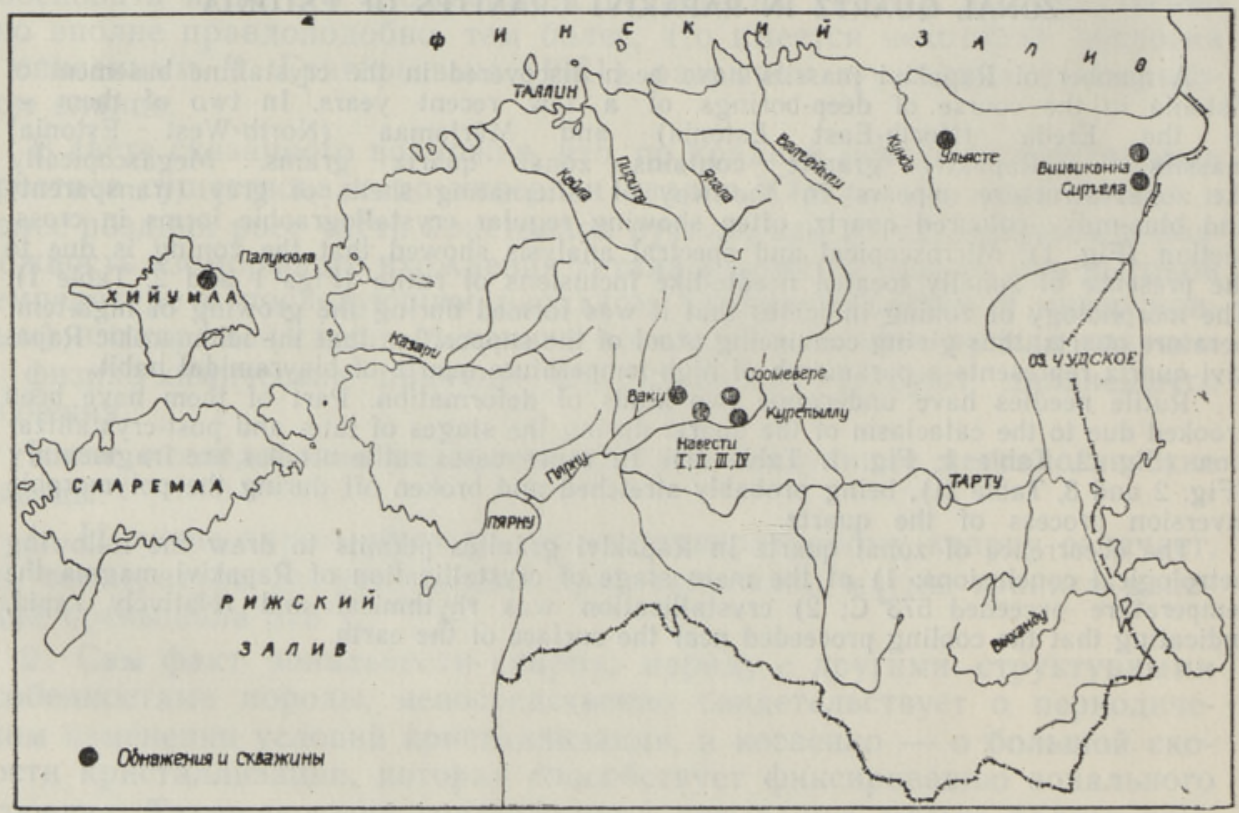

Схематическая карта распространения наиболее известных свинцово-цинкивьм. рудопроявлений. 
Пробы исследовались под бинокулярным микроскопом и отбирались мономинеральные фракции для спектрального анализа.

Спектральным анализом были выявлены следующие элементы: таллий, галлий, германий, индий, кадмий, висмут, серебро и сурьма.

Анализы были выполнены главным образом Х. Хедреярвом по его же методу (Хедреярв, 1967). Чувствительность определения рассеянных в галените и сфалерите элементов (в процентах):

$$
\begin{gathered}
\mathrm{Tl}-2,5 \cdot 10^{-5} ; \mathrm{Cd}-2,2 \cdot 10^{-3} ; \text { In }-9,2 \cdot 10^{-6} ; \mathrm{Ga}-2,4 \cdot 10^{-4} \\
\mathrm{Ge}-2,3 \cdot 10^{-4} ; \mathrm{Bi}-6,3 \cdot 10^{-5} ; \mathrm{Ag}-1,8 \cdot 10^{-5}
\end{gathered}
$$

Приведем основные результаты геохимических исследований минералов галенита и сфалерита.

Таллий. Минералами-носителями таллия в рудопроявлениях Эстонии являются галенит, сфалерит и пирит (последний в данном случае не изучался).

Из табл. 1 и 2 видно, что наиболее обогащенными таллием являются кристаллы сфалерита из Ваки $\left(8,2 \cdot 10^{-3} \%\right)$, содержащие кроме того много железа. Как поқазывают исследования В. Иванова (1966), в поздних порциях низкотемпературных гидротермальных растворов количество таллия в карбонатных породах часто увеличивается. В ряде случаев в низкотемпературных свинцово-цинковых рудах концентрация таллия в колломорфных сульфидных образованиях достигает нескольких десятых долей процента. В Центральной и Северо-Восточной Эстонии колломорфные образования сфалерита встречаются часто, но поскольку содержание таллия в них низкое, можно предположить, что в Эстонии свинцово-цинковые минералы отлагались из слабонасыщенных низкотемпературных рудоносных растворов.

Среднее содержание элементов в кристаллах галенита, \%

\begin{tabular}{l|l|l|l|l|l|l|l}
\hline $\begin{array}{c}\text { Местонахождение } \\
\text { рудопроявления }\end{array}$ & $\begin{array}{l}\text { Число } \\
\text { проб }\end{array}$ & $\mathrm{Tl}$ & $\mathrm{Cd}$ & $\mathrm{In}$ & $\mathrm{Ag}$ & $\mathrm{Sb}$ & $\mathrm{Bi}$ \\
\hline
\end{tabular}

Нн жний силур, адавереский горизонт, трещиноватые доломиты

Навести I, обнажение

Навести II,

Навести III, "

Навести IV, ,"

Курепыллу, шурф

Ваки, скважины, обнажение

С редний ордовик,

$\begin{array}{rrrrr}117 & 6,5 \cdot 10^{-5} 3,7 \cdot 10^{-3} 5,7 \cdot 10^{-5} 3,7 \cdot 10^{-5} 1,6 \cdot 10^{-2} & 10^{-4} \\ 3 & 2,4 \cdot 10^{-5} & 10^{-3} 3,9 \cdot 10^{-5} 5,6 \cdot 10^{-5} 1,3 \cdot 10^{-2} & 10^{-4} \\ 120 & 3,1 \cdot 10^{-5} & 2 \cdot 10^{-3} 2,7 \cdot 10^{-5} 3,5 \cdot 10^{-5} 1,2 \cdot 10^{-2} & 10^{-4} \\ 5 & 2 \cdot 10^{-5} 2,3 \cdot 10^{-3} 3,4 \cdot 10^{-5} 2,2 \cdot 10^{-5} 1,2 \cdot 10^{-2} & 10^{-4} \\ 3 & 9,1 \cdot 10^{-6} & 10^{-3} 2,3 \cdot 10^{-5} 8,1 \cdot 10^{-5} 1,3 \cdot 10^{-2} & 10^{-4} \\ 22 & 8,2 \cdot 10^{-3} & 10^{-3} 4,6 \cdot 10^{-4} 4,5 \cdot 10^{-4} 1,5 \cdot 10^{-2} & 10^{-4}\end{array}$

кукрузеский горизонт, трещиноватые доломитизированные известняки

Вийвиконна, рудник

Сиргала,
Д окемб ри й, трещиноватые мигматитовые гнейсы и амфиболиты

Палукюла, скважина

$43 \quad 5 \cdot 10^{-5} \quad 10^{-3} \quad 3 \cdot 10^{-5} 1,3 \cdot 10^{-3} 1,9 \cdot 10^{-2} 3 \cdot 10^{-4}$

$19 \cdot 10^{-4 *} \mathrm{He}$ onp. He onp. He onp. He onp. He onp.

$3 \quad 5 \cdot 10^{-6} 1,6 \cdot 10^{-2} \quad 3 \cdot 10^{-5} 1,9 \cdot 10^{-3} 1,9 \cdot 10^{-2} \quad 10^{-4}$

* По Н. Воскресенской (1969).

4 ENSV TA Toimetised $\mathrm{K} * \mathrm{G}-1$ 1971 
Кадмий. Главным минералом-носителем кадмия в рудопроявлениях Әстонии является сфалерит, но иногда он присутствует и в галените (см. табл. 1,2 ).

таблица 2

Среднее содержание элементов в кристаллах сфалерита, \%

\begin{tabular}{l|l|l|l|l|l|l}
\hline Местонахождение рудопроявления & $\begin{array}{l}\text { Число } \\
\text { проб }\end{array}$ & $\mathrm{Tl}$ & $\mathrm{Cd}$ & -In & $\mathrm{Ga}$ & $\mathrm{Ge}$ \\
\hline
\end{tabular}

Нижний силур, адавереский горизонт, трещиноватые доломиты

Навести I, обнажение

Навести II, ,

Навести III, ",

Соомевере, скважина

Ваки,

$"$

С редний ордо"вик, кукрузеский горизонт, трещиноватые доломитизированные известняки

Вийвиконна, рудник

Сиргала,

Д окембри й, мигматитовые гнейсы, кварциты, мраморы Ульясте, скважина, гл. 190,4 $~$

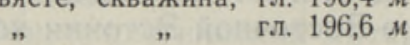

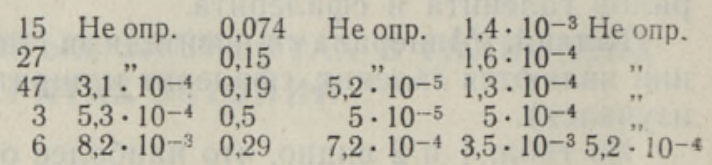

* По Н. Воскресенской (1969).

$92,3 \cdot 10^{-4} \quad 0,15 \quad 4 \cdot 10^{-5} \quad 10^{-4}$ He onp.

$13,5 \cdot 10^{-4 *}$ He onp. He onp. He onp.
$10^{-3} \quad 10^{-2}$ $10^{-3} \quad 10^{-3}$

Довольно высокая концентрация кадмия $(0,4-0,7 \%)$ установлена в кристаллах сфалерита из скв. Ульясте, где рудопроявление развито в докембрийских кварцитах, гнейсах и гранитах.

При сравнении содержания кадмия в сфалеритах Центральной и Северо-Восточной Эстонии больших различий не наблюдается, так как и те и другие образовались в карбонатной среде. В рудопроявлениях Ульясте и Палукюла сфалериты образовались в силикат-сульфидной среде и, вероятно, поэтому содержание кадмия отличается от содержания его в других местонахождениях.

Индий является малораспространенным элементом земной коры и находится преимущественно в рассеянном состоянии. Минералами-носителями индия в Әстонии являются в основном галенит и сфалерит, где, как показывают наши исследования, его содержание очень незначительно. Максимально оно в галените из скважин Ваки $\left(4,6 \cdot 10^{-4} \%\right)$ и в руднике Вийвиконна $\left(3 \cdot 10^{-5} \%\right)$, а в обнажениях р. Навести -- минимально.

По данным В. Иванова (1966) и других авторов, индионосными являются только довольно высокотемпературные гидротермальные руды.

Галлий. Основным минералом-носителем галлия в Эстонии является сфалерит; в галените он не установлен. Наибольшее количество его $\left(3,5 \cdot 10^{-3} \%\right)$ в сфалерите встречается в районе Ваки. Как показывают наши исследования, сфалерит из гранитов и гнейсов скв. Ульясте и сфалерит из доломитов и доломитизированных известняков Центральной и Северо-Восточной Эстонии характеризуются близкой галлиеносностью.

Германий установлен нами только в сфалеритах карбонатных пород из обнажения и скважин Ваки $\left(5,2 \cdot 10^{-4} \%\right)$, а также в сфалеритах из гранитогнейсов докембрия в Северной Эсгонии (в скв. Ульясте до $10^{-2} \%$ ). 
Несмотря на то, что свинцово-цинковые низкотемпературные руды в карбонатных породах наиболее благоприятны для накопления германия (Жукова, 1964; Иванов, 1966; Graton, Harcourt, 1935 и др.), концентрация его в сфалеритах Эстонии особенно низкая. Это можно объяснить тем, что в Эстонии рудоносные растворы, проникавшие в протерозойские и палеозойские породы, были вообще слабо насыщены рудными элементами.

Серебро - широко распространенный элемент в эстонских галеннтах, где его максимальное содержание составляет $1,9 \cdot 10^{-3} \%$. Из данных спектрального анализа (табл. 1) следует, что концентрация серебра в галенитах из Навести, Ваки, Вийвиконна и Палукюла изменяется в довольно значительных пределах, что указывает на возможную вертикальную зональность рудопроявления. Небольшое количество серебра в галените говорит о том, что оно отлагалось из малонасыщенных рудоносных растворов.

В Северо-Восточной Эстонии около Вийвиконна и Сиргала содержание серебра в рудовмещающих породах колеблется в пределах $(2 \div 6) \cdot 10^{-4} \%$ и редко составляет $2 \cdot 10^{-3} \%$, а в Центральной Эстонии, в Соомевере - в пределах $(1,8 \div 2,8) \cdot 10^{-4} \%$.

Сурьма сравнительно широко распространена в галенитах Эстонии. По А. Ферсману (1959), она относится к низкотемпературным элементам. Сурьма обнаружена нами во всех пробах галенита, причем ее содержание в Центральной и Северо-Восточной Эстонии почти одинаково (см. табл. 1). Близкое содержание сурьмы в галенитах различных месторождений, по всей вероятности, указывает на то, что в Эстонии выпадание свинцово-цинковой руды из малонасыщенных рудоносных растворов происходило в одинаковых условиях.

Висмут - относительно редкий элемент и, по А. Ферсману (1959), отлагается из высоко- и среднетемпературных гидротермальных растворов. Минералом-носителем висмута в Эстонии является галенит, где его содержание очень низкое $\left(10^{-4} \%\right)$. Поэтому в пробах висмут часто не обнаруживается: он установлен лишь в единичных случаях из галенита Вийвиконна и Палукюла.

Приведенный здесь фактический материал показывает, что концентрация элементов: $\mathrm{Tl}$, In, $\mathrm{Cd}, \mathrm{Ge}, \mathrm{Ga}, \mathrm{Bi}, \mathrm{Ag}$ и $\mathrm{Sb}$ в галенитах и сфалеритах Эстонии очень низкая по сравнению с данными о низкотемпературных свинцово-цинковых месторождениях карбонатных пород в различных районах СССР (Власов и др., 1966; Иванов, 1966) и зарубежных стран (Schroll, 1955; Harańczyk, 1957; Ohle, 1959 и др.).

В связи с изложенным выше возникает вопрос: какие природные факторы определяли концентрацию и миграцию рассеянных элементов при образовании свинцово-цинковых руд на территории Эстонии? Решению этого вопроса должно способствовать знание геологических условий рудообразования.

Из современных геологических и геофизических исследований Эстонской ССР (Пальмре, 1960, 1964, 1967; Вахер и др., 1964 и др.) следует, что низкотемпературные гидротермальные свинцово-цинковые рудопроявления не имеют промышленного значения.

Исследования Р. Вахера и др. (1962), Э. Побула (1962), В. Маазика (1964) и других авторов показывают, что тектонические разломы, с которыми связаны свинцово-цинковые рудопроявления, не охватывают глубоких частей земной коры.

Из работ А. Ферсмана (1959), В. Щербиной (1968), И. Гинзбурга и др. (1966) известно, что в условиях слабого насыщения и медленно идущей кристаллизации число элементов, изоморфно замещающих главные 
компоненты минерала, значительно меньше, чем в случае кристаллов, образовавшихся из сильнопересыщенных растворов.

С другой стороны, благодаря работам А. Пейве $(1956,1961)$, Ф. Вольфсона $(1948,1962)$, В. Иванова (1966), К. Власова (1966), Е. Радкевича (1963) и других, известно, что многие обогащенные рассеянными элементами гидротермальные свинцово-цинковые месторождения четко приурочены к зонам глубоких тектонических разломов, которые в современном срезе прослежены на сотни и даже тысячи километров. Так, В. Иванов (1966) и другие считают установленным, что глубинные разломы, с которыми связаны гидротермальные месторождения, обогащенные рассеянными элементами, проникают на весьма значительную глубину. Естественно, что именно эти тектонические линии являются теми путями, по которым осуществляется наиболее интенсивная геохимическая миграция компонентов глубинного вещества.

Принимая во внимание приведенные выше точки зрения, данные наших анализов, а также регионально-геологическое положение Эстонии, можно сказать, что по существующим в Эстонии текгоническим разломам из неглубоких зон земной коры поднимались слабонасыщенные низкотемпературные рудоносные гидротермальные растворы, из которых в ничтожном количестве отлагались рудные вещества - свинец и цинк, а вместе с ними в небольшом количестве и рассеянные элементы: таллий, индий, кадмий, галлий, германий, висмут, серебро и сурьма.

\section{ЛИТ Е РА Т РА}

В ах ер Р., П у ур а В., Эр и с а л у Э. 1962. Тектоническое строение Северо-Восточной Эстонии. Тр. Ин-та геол. АН ЭССР, $\mathbf{X .}$

В ахер Р., К у усп ал у Т., Пу ур а В., Эри са л у Э. 1964. О геологическом положении сульфидных рудопроявлений в районе Ульясте. В сб.: Литология палеозойских отложений Эстонии. Таллин.

В ласо в К. А. и др. 1966. Геохимия, минералогия и генетические типы месторожденнй редких элементов, т. I-III. М.

В оль фсон Ф. И. 1948. Отношение оруденения эндогенных месторождений к крупным тектоническим нарушениям. Изв. АН СССР, Серия геол., № 6.

В оль фсон Ф. И. 1962. Проблемы изучения гидротермальных месторождений. М.

В оск рес ен ска я Н. Т. 1969. Таллий в осадочных сульфидах. Геохимия, № 3.

Г и н $з$ б р г И. И. и др. (1966). Применение геохимических методов при металлогенических исследованиях рудных районов. М.

Ж уков а А. С. 1964. Германий. В кн.: Геохимия, минералогия и генетические типы месторождений редких элементов, г. 2. М.

И в а н ов В. В. 1966. Геохимия рассеянных элементов Ga, Ge, Cd, In, Tl в гидротермальных месторождениях. M.

М а а з и к В. 1964. О гравиметрической разведке полиметаллического рудопроявления в северной части Эстонии. В сб.: Литология палеозойских отложений Эстонии. Таллин.

Пальм р Х. 1960. Закономерности полиметаллического оруденения на территорни Эстонской ССР. Киев.

П ал в м р е Х., И о х н н е с Э. 1964. О некоторых микроэлементах в сульфидных минералах Эстонии. В сб.: Литология палеозойских отложений Эстонии. Таллин.

П а ль м р е X. 1967. Текстурные особенности руд свинцово-цинкового рудопроявления в Эстонской ССР. Изв. АН ЭССР, Хим. Геол., 16, № 3.

Побул Э. 1962. О строении кристаллического фундамента Эстонии по данным геофизики. Тр. Ин-та геол. АН ЭССР, Х.

П ей в е А. В. 1956. Связь осадконакопления, складчатости, магматизма и минеральных месторождений с глубинными разломами. Изв. АН СССР, Серия геол., № 3.

П е й в е А. В. 1961. Тектоника и магматизм. Изв. АН СССР, Серия геол., № 3.

Р а дке в и ч Е. А. 1963. К вопросу о типах зональности в оловянных и полиметаллических месторождениях Тихоокеанского рудного пояса. В кн.: Проблемы постмагматического рудообразования с особым вниманием к геохимии рудных жил, т. 1. Прага.

$\Phi$ е р с м н А. Е. 1959. Избранные труды, т. V. М. 
Хед дея в В X. 1967. Разработка химико-спектральных методов определения редких в рассеянных элементов в эстонских галенитах. Автореф. канд. дисс. Таллин.

Щ е рб ин а В. В. 1968 . Влияние степени пересыщения сульфидных растворов на характер эндогенного рудообразования. Междунар. геол. конгресс, XXIII сессия. Докл. сов. геол. Эндогенные рудные месторождения. М.

Prewer F., C ox J. D., Morris D. F. C. 1955. The occurrence of germanium in blende. Geochin. et cosmochim Acta, 8, No, 3.

Graton L. C., Harcourt G. A. 1935. Spectrographic evidence on origin of ores of Mississippi Valley type. Econ. Geol., 30, No. 7.

H a r a n c z y k C. 1957. Pierwiatki slodowa w mineralach Kruszcowych ze slosko-krakowskich zloz cynkowo-olowianych. Biul. Inst. geol., No. 155.

Oh le E. L. 1959. Some considerations in determining the origin of ore deposits of the Mississippi Valley type. Econ. Geol., 54, No. 5.

$\mathrm{Schro11}$ E. 1955. Uber das Vorkommen einiger Spurenmetalle in Blei-Zink-Erzen de: ostalpiner Metallprovinz. Tschermaks mineral. und petrogr. Mitt. Folge, 3. Wien.

Ннститут химии
Ака๘емии наук Эстонской ССР

Поступила в редакцию

$14 / \mathrm{IV} 1970$

\section{H. PALMRE}

\section{MONINGATEST HAJUTATUd ELEMENTIDEST EESTI GALENIIDIS JA SFALERIIDIS}

Galeniidi ja sfaleriidi spektraalanalüütiline uurimine näitas, et nendes mineraalides esineb hajutatud galliumi, germaaniumi, indiumi, kaadmiumi, talliumi ja vismutit väga vähesel hulgal. See vihjab tôenäoliselt sellele, et maakikandvad lahused olid madala kontsentratsiooniga ja temperatuuriga, kusjuures nad tõusid üles tektooniliste lõhede või murrangute kaudu, millede sügavushaare maakoores geofüüsikaliste andmete alusel on väike.

\section{H. PALMRE}

\section{ON SOME TRACE ELEMENTS IN ESTONIAN GALENA AND SPHALERITES}

The spectral analysis of Estonian galena and sphalerites revealed that in those minerals the content of trace elements of gallium, germanium, indium, cadmium, thallium, and bismuth is very low. This probably points to the fact that the ore-bearing solutions were of a low concentration and temperature and penetrated higher through tectonic faults or fissures whose depth range in the Earth's crust, accordirg to geophysical data, was iriconsiderable. 